\title{
The genes controlling sucrose utilization in Clostridium beijerinckii NCIMB 8052 constitute an operon
}

\author{
Sharon J. Reid, M. Suhail Rafudeen and Neil G. Leat \\ Author for correspondence: Sharon J. Reid. Tel: +27 21650 3257. Fax : +27 216897573. \\ e-mail:shez@molbiol.uct.ac.za
}

Department of

Microbiology, University of Cape Town, Rondebosch

7700 , South Africa
The sucrose operon of Clostridium beijerinckii NCIMB 8052 comprises four genes, which encode a sucrose-specific enzyme IIBC ${ }^{S c r}$ protein of the phosphotransferase system (ScrA), a transcriptional repressor (ScrR), a sucrose hydrolase (ScrB) and an ATP-dependent fructokinase (ScrK). The scrARBK operon was cloned in Escherichia coli in three stages. Initial isolation was achieved by screening a $C$. beijerinckii genomic library in $E$. coli for clones able to utilize sucrose, while the remainder of the operon was isolated by inverse PCR and by plasmid rescue of flanking regions from a scrB mutant constructed by targeted gene disruption. Substrate specificity assays confirmed that the sucrose hydrolase was a $\beta$-fructofuranosidase, able to hydrolyse sucrose and raffinose but not inulin or levans, and that the scrK gene encoded an ATP/Mg ${ }^{2+}$ dependent fructokinase. Both enzyme activities were induced by sucrose in $C$. beijerinckii. Disruption of the scr operon of $C$. beijerinckii by targeted plasmid integration into either the scrR or the ScrB gene resulted in strains unable to utilize sucrose, indicating that this was the only inducible sucrose catabolic pathway in this organism. RNA analysis confirmed that the genes of the scr operon were co-transcribed on a 5 kb mRNA transcript and that transcription was induced by sucrose, but not by glucose, fructose, maltose or xylose. Primer extension experiments identified the transcriptional start site as lying $\mathbf{4 4}$ bp upstream of the scrA ATG start codon, immediately adjacent to the imperfect palindrome sequence proposed to be a repressor binding site. Disruption of the scrR gene resulted in constitutive transcription of the upstream scrA gene, suggesting that scrR encodes a transcriptional repressor which acts at the scrA operator sequence. The scrR gene is therefore itself negatively autoregulated as part of the polycistronic SCrARBK mRNA.

Keywords: Clostridium beijerinckii, sucrose PTS, sucrose hydrolase, fructokinase, coordinated induction

\section{INTRODUCTION}

Solventogenic strains of the Clostridium acetobutylicum/C. beijerinckii group have been used for production of acetone and butanol in the classical acetone-butanol-ethanol (ABE) fermentation (Woods, 1993). Industrial ABE fermentations were initially based

Abbreviation: PTS, phosphoenolpyruvate-dependent phosphotransferase stystem.

The GenBank accession number for the $C$. beijerinckii scrARBK operon is AF059741. on starch, but subsequently molasses became the primary substrate, and saccharolytic clostridial strains from three distinct taxonomic groups were isolated (Johnson \& Chen, 1995; Jones \& Keis, 1995; Woods, 1993). C. beijerinckii NCIMB 8052 (formerly C. acetobutylicum; Keis et al., 1995) was one of these mesophilic, obligately anaerobic spore-forming bacteria isolated for its ability to ferment molasses. Although the disaccharide sucrose is a major constituent of molasses and optimal utilization of the carbohydrate substrate is essential for high yields in the ABE fermentation, the genes involved in sucrose utilization in the saccharolytic clostridia have not been identified and characterized. 
Sucrose metabolism has been well characterized in several Gram-positive bacterial species (Steinmetz, 1993) and sucrose has been shown to be metabolized by extracellular as well as intracellular enzyme systems. Extracellular enzymes capable of sucrose hydrolysis include $\beta$-fructosyltransferases and $\alpha$-glucosyltransferases, which catalyse the hydrolysis of sucrose and the synthesis of fructose and glucose polymers respectively (Steinmetz, 1993). Where sucrose is catabolized intracellularly, the predominant mechanism facilitating sucrose uptake is the phosphoenolpyruvate-dependent phosphotransferase stystem (PTS) (Saier \& Reizer, 1992), which results in the accumulation of intracellular sucrose 6-phosphate. Transport and phosphorylation of the carbohydrate is mediated by the sucrose-specific Enzyme II (EII $\left.{ }^{\text {Scr }}\right)$. The sucrose 6-phosphate is further metabolized by sucrose-6-phosphate hydrolases, yielding glucose 6-phosphate and fructose. In some species, fructokinases phosphorylate the fructose generated by sucrose hydrolysis, so that both products can be incorporated into the glycolytic pathway.

The components of the glucose PTS have been identified in C. beijerinckii 8052 (Mitchell et al., 1991), and the presence of Enzyme I, $\mathrm{HPr}$ and the glucose-specific membrane-associated Enzyme II proteins was confirmed by complementation of cell extracts with extracts prepared from PTS mutants of Escherichia coli or Bacillus subtilis. Studies on the metabolism of several other sugars by $C$. beijerinckii have established that PTS-mediated sugar uptake appears to be the predominant carbohydrate transport mechanism in this bacterium and PTS-dependent transport mechanisms have been specifically proposed for sucrose, fructose, glucitol, mannitol and lactose. Non-PTS uptake systems, however, are thought to play a role in galactose and maltose uptake (Mitchell et al., 1995; Tangney et al., 1998). Recent evidence confirmed the presence of all three components of a sucrose-specific PTS in C. beijerinckii (Tangney et al., 1998).

PTS permeases contain two peripheral membrane domains (IIA and IIB) as well as an integral membrane domain (IIC), all of which may be contained within a single polypeptide chain (Saier \& Reizer, 1992). Analysis of several sucrose transport systems indicates that in Streptococcus mutans (Sato et al., 1989), Streptococcus sobrinus (Chen et al., 1993) and Pediococcus pentosaceus (GenBank accession L32093) the EII ${ }^{\text {Scr }}$ proteins consist of EIIB, EIIC and EIIA domains, fused by linker regions (EIIBCA ${ }^{\mathrm{Scr}}$ proteins). In other cases, such as Klebsiella pneumoniae, Salmonella typhimurium and Vibrio alginolyticus, the EII ${ }^{\text {Scr }}$ proteins simply consist of fused EIIBC ${ }^{\text {Scr }}$ domains (Blatch et al., 1990; Lengeler et al., 1994).

Sucrose-catabolic genes are often clustered on the genome, as is the case with V. alginolyticus (Blatch et al., 1990), B. subtilis (Fouet et al., 1986, 1987) and Strep. mutans (Sato et al., 1989), or on transposons or plasmids, as in enteric bacteria (Bockmann et al., 1992; Titgemeyer et al., 1996). The arrangement and transcrip- tional organization of these clusters differ in each species, suggesting a modular evolution of these systems. These sucrose-utilization regions invariably contain genes encoding a sucrose hydrolase and a sucrose transport protein, but also may be clustered with other $s c r$-specific genes, such as fructokinase and regulator genes. The genes encoding regulatory proteins associated with sucrose-catabolic genes are functionally diverse. In B. subtilis, the expression of sucrose-catabolic genes is regulated by transcriptional antiterminators (Arnaud et al., 1992), while in Staphylococcus xylosus, $V$. alginolyticus, Sal. typhimurium and K. pneumoniae regulation is achieved by transcriptional repressors of the GalR-LacI family (Blatch et al., 1990; Bockmann et al., 1992; Jahreis \& Lengeler, 1993). In most other sucrose-utilization regulons, with the exception of Lactococcus lactis (Rauch \& de Vos, 1992), the corresponding $s c r R$ genes are independently transcribed, and no examples where all the genes are co-ordinately controlled as an operon have hitherto been described.

In this paper we report the isolation and characterization of a sucrose-utilization operon from $C$. beijerinckii NCIMB 8052, and demonstrate the genetic organization and transcriptional regulation of the genes. The scr operon of C. beijerinckii, unlike the other sucroseutilization regulons reported to date, contains all the genes required for sucrose uptake, hydrolysis and the subsequent phosphorylation of the products, under coordinated control of the repressor gene, scrR.

\section{METHODS}

Bacterial strains, plasmids and culture conditions. C. beijerinckii NCIMB 8052 was routinely cultured at $37^{\circ} \mathrm{C}$ using Clostridial Basal Medium (CBM) (Jones et al., 1982) or Reinforced Clostridial Medium (RCM) (Difco) in an anaerobic cabinet with a gas phase of $5 \% \mathrm{H}_{2}, 10 \% \mathrm{CO}_{2}$ and $85 \% \mathrm{~N}_{2}$ (Forma Scientifica). Where appropriate, erythromycin was used at a final concentration of $10 \mu \mathrm{g} \mathrm{ml} \mathrm{m}^{-1}$. Carbohydrate studies were performed on cells grown in GSMM medium (Jones et al., 1982) supplemented with $0 \cdot 2 \%$ Casamino acids (Difco) and with the appropriate carbohydrate $(0 \cdot 25 \%, \mathrm{w} / \mathrm{v})$.

E. coli strains and plasmids are listed in Table 1. JM109 (Sambrook et al., 1989) was used for all cloning purposes and was routinely cultured at $37^{\circ} \mathrm{C}$ on Yeast Tryptone (YT) or Luria-Bertani (LB) medium (Sambrook et al., 1989). MacConkey agar medium (Difco) supplemented with either sucrose $(1 \%, w / v)$ or lactose $(1 \%, w / v)$ was used to assess carbohydrate fermentation phenotypes. E. coli CA474, a $\lambda$ cl857 lysogen of $E$. coli HB101 (Wilkinson \& Young, 1994) was used as a donor in transconjugation experiments and was cultured on Brain Heart Infusion (BHI) medium (Difco). Ampicillin $\left(100 \mu \mathrm{g} \mathrm{m}^{-1}\right)$ and kanamycin $\left(100 \mu \mathrm{g} \mathrm{ml}^{-1}\right)$ were included in media where appropriate.

Nucleic acid isolation and manipulation. DNA and RNA manipulations were carried out by standard methods (Sambrook et al., 1989). Plasmid DNA was extracted and purified from E. coli using the Nucleobond AX KIT (MachereyNagel). T4 DNA ligase and DNA restriction endonucleases were obtained from Boehringer and were used according to 
Table 1. Bacterial strains and plasmids used in this study

\begin{tabular}{|c|c|c|}
\hline Strain or plasmid & Relevant characteristics ${ }^{*}$ & Reference or source \\
\hline \multicolumn{3}{|l|}{ C. beijerinckii } \\
\hline NCIMB 8052 & Prototrophic & NCIMB Culture Collection \\
\hline CBSCRB & scrB::erm & This study \\
\hline CBSCRR & scrR::erm & This study \\
\hline \multicolumn{3}{|l|}{ E. coli } \\
\hline JM109 & $\begin{array}{l}\text { recA1 end } 1 \text { gyrA96 thi hsdR17 supE44 } \\
\text { relA1 } \lambda^{-} \Delta(\text { lac-pro } A B)\left(\mathrm{F}^{\prime}, \text { traD36 pro } A B\right. \\
\left.\text { lacl }^{\mathrm{C}} \mathrm{Z} \Delta \mathrm{M} 15\right)\end{array}$ & Sambrook et al. (1989) \\
\hline CA474 & $\begin{array}{l}\left.\mathrm{F}^{-} \lambda \text { cl857 hsdS20( } \mathrm{r}_{\mathrm{B}}^{-} \mathrm{m}_{\mathrm{B}}^{-}\right) \operatorname{supE} 44 \text { aro-14 } \\
\text { galK2 lacY1 proA2 rpsL20 }\left(\mathrm{Sm}^{\mathrm{R}}\right) \text { xyl-5 } \\
\text { mtl-1 recA13 }\end{array}$ & Wilkinson \& Young (1994) \\
\hline \multicolumn{3}{|l|}{ Plasmids } \\
\hline pBluescript SK (pSK) & $\mathrm{Amp}^{\mathrm{R}}$ lac $Z^{\prime}$ & Stratagene \\
\hline $\mathrm{pEcoR} 251$ & $\operatorname{Amp}^{R}(E c o R I)$ & Zabeau \& Stanley (1982) \\
\hline pACYC177 & $A m p^{R} K m^{R}$ & Chang \& Cohen (1978) \\
\hline R702 & $\mathrm{Km}^{\mathrm{R}} ; \mathrm{Tra}^{+} \mathrm{Mob}^{+}$ & Wilkinson \& Young (1994) \\
\hline pMTL30 & $\mathrm{Amp}^{\mathrm{R}} \mathrm{Em}^{\mathrm{R}} ; \mathrm{Tra}^{-} \mathrm{Mob}^{+}$ & Williams et al. (1990) \\
\hline pCTC1 & $\mathrm{Amp}^{\mathrm{R}} \mathrm{Em}^{\mathrm{R}} ; \mathrm{Tra}^{-} \mathrm{Mob}^{+}$ & Williams et al. (1990) \\
\hline pCBS1 & $\begin{array}{l}\text { Amp }{ }^{\mathrm{R}} ; 6.8 \mathrm{~kb} \text { Sau3A C. beijerinckii } \\
\text { fragment in pEcoR } 251\end{array}$ & This study \\
\hline pCBS2 & $\begin{array}{l}\mathrm{Amp}^{\mathrm{R}} ; 3 \mathrm{~kb} S c a \mathrm{I} \text { fragment from pCBS1 in } \\
\mathrm{pSK} E c o \mathrm{RV} \text { site }\end{array}$ & This study \\
\hline pCBS3 & $\begin{array}{l}\mathrm{Amp}^{\mathrm{R}} \mathrm{Em}^{\mathrm{R}} ; 3.2 \mathrm{~kb} \text { HindIII-NdeI fragment } \\
\text { recovered from CBSCRB }\end{array}$ & This study \\
\hline pCBS4 & $\begin{array}{l}\mathrm{Amp}^{\mathrm{R}} \mathrm{Km}^{\mathrm{s}} ; 1.2 \mathrm{~kb} \text { isolated from } \\
\text { C. beijerinckii by PCR }\end{array}$ & This study \\
\hline pCBMU1 & $\begin{array}{l}A m p^{\mathrm{R}} \mathrm{Em}^{\mathrm{R}} ; \mathrm{pMTL} 30 \text { with internal } 435 \mathrm{bp} \\
s c r B \text { fragment }\end{array}$ & This study \\
\hline pCBMU3 & $\begin{array}{l}\mathrm{Amp}^{\mathrm{R}} \mathrm{Em}^{\mathrm{R}} \text {; pMTL30 with internal } 456 \mathrm{bp} \\
\text { scrR fragment }\end{array}$ & This study \\
\hline
\end{tabular}

${ }^{*} \mathrm{Sm}^{\mathrm{R}}, \mathrm{Amp}^{\mathrm{R}}, \mathrm{Km}^{\mathrm{R}}, \mathrm{Em}^{\mathrm{R}}$, resistance to streptomycin, ampicillin, kanamycin and erythromycin respectively; Tra, Mob, ability of plasmids to transfer or to be mobilized by conjugation respectively.

the manufacturer's recommendations. Chromosomal DNA was isolated from C. beijerinckii as described by Collett et al. (1997). The C. beijerinckii genomic library was constructed by partially digesting chromosomal DNA with Sau3A, and ligating DNA fragments of between 5 and $11 \mathrm{~kb}$ into the $B g l \mathrm{II}$ site of the positive selection vector, pEcoR251 (Table 1). Total RNA was isolated from C. beijerinckii as described previously (Youngleson et al., 1995). DIG-labelled RNA probes, specific for the transcripts of the $s c r A, s c r R, s c r B$ and $s c r K$ genes, were prepared and hybridized according to standard techniques specified by Boehringer. Primer extension experiments were carried out according to Ausubel et al. (1989), with the addition of actinomycin $\mathrm{D}\left(0.225 \mathrm{mg} \mathrm{ml}^{-1}\right)$. The primers used were: primer c (scrA gene: 5'-TTCTTTTGCTACTATTTGTTCC-3') and primer d (scrK gene: 5'-TTATCTACACAAAGCATATC-3').

Targeted integration of plasmids into the $C$. beijerinckii genome. The targeted integration system developed by Wilkinson \& Young (1994) involves the mobilization of the suicide vector, pMTL30, carrying short regions of C. beijerinckii 'target' DNA, into $C$. beijerinckii. pCBMU1 was constructed by cloning the $435 \mathrm{bp} \mathrm{NdeI} \mathrm{fragment} \mathrm{internal} \mathrm{to}$ $s c r B$ from pCBS1 into the StuI site of pMTL30, and pCBMU3 by cloning the $456 \mathrm{bp}$ HindII-Scal fragment internal to $s c r R$ from pCBS1 into pMTL30 (Table 1, Fig. 1). E. coli CA474, containing the mobilizing plasmid $\mathrm{R} 702$ and the relevant pMTL30 derivative, was conjugated with $C$. beijerinckii cultures as described by Wilkinson \& Young (1994), with incubation anaerobically at $30^{\circ} \mathrm{C}$ for $18 \mathrm{~h}$ to prevent induction of the $\lambda$ prophage of CA474 (Table 1). Selection of $C$. beijerinckii transconjugants was facilitated by plating onto CBM agar plates containing $10 \mu \mathrm{g}$ erythromycin $\mathrm{ml}^{-1}$ and incubating anaerobically at $42{ }^{\circ} \mathrm{C}$ for $18 \mathrm{~h}$ to enhance counterselection of the donor strain by induction of the $\lambda$ prophage. Southern blot analysis was used to verify that the $s c r R$ and $s c r B$ genes had been disrupted in C. beijerinckii CBSCRR and CBSCRB respectively. The hybridization pattern indicated that in both cases, multiple copies of the plasmids had integrated into the genes.

Recovery of integrated plasmids from the $C$. beijerinckii genome. Genomic DNA was isolated from CBSCRB, the C. beijerinckii strain carrying chromosomally integrated copies of pCBMU1 in the $s c r B$ gene (Table 1). The isolated DNA was digested with HindIII, and self-ligated (10 ng DNA per $30 \mu \mathrm{l}$ 
ligation reaction). E. coli JM109 transformants were screened for ampicillin resistance on YT agar medium containing ampicillin $\left(100 \mu \mathrm{g} \mathrm{ml}^{-1}\right)$.

PCR amplification of DNA from the $C$. beijerinckii genome. An inverse-PCR strategy as described by Sambrook et al. (1989) was used to amplify the $5^{\prime}$ region of the C. beijerinckii sucrose-utilization system. Chromosomal DNA was digested with $X m n I$ and self-ligated (200 ng DNA per $50 \mu$ l ligation). Two divergent primers, primer a $\left(5^{\prime}\right.$-TATTATAGGTACAAATACATCTCC-3') and primer b (5'-ATATGTGAGCGAAGAAAATGC-3') were designed from the known sequence of the $s c r R$ gene, and were used for inverse PCR with the self-ligated chromosomal DNA as a template (Fig. 1). PCR reactions were conducted using an OmniGene thermocycler (Hybaid) and Taq DNA polymerase (Advanced Biotechnologies). The amplified fragment was cloned into the SmaI site of the low-copy-number vector pACYC177 (Chang \& Cohen, 1978).

Nucleotide sequencing. DNA sequencing was carried out as described previously (Collett et al., 1997) or with the Sequitherm kit (Epicentre Technologies) using CY-5 labelled M13 primers and an OmniGene thermocycler (Hybaid). Where CY-5 label was used, nucleotide sequence was resolved using an Alfexpress automated DNA sequencer (Pharmacia). The current databases were screened for similarities to the DNA and deduced protein sequences using the BLAST program of the National Centre for Biotechnology Information (NCBI), and further analysed with the programs in the Genetics Computer Group (GCG) sequence analysis package (Devereux et al., 1984). Phylogenetic analysis was conducted using the CLUSTAL w algorithm of Thompson et al. (1994), and the results were rendered using the TreeView software package (R. D. M. Page, 1996, Institute of Biomedical and Life Sciences, University of Glasgow).

Enzyme and protein assays. Sucrose hydrolase activity was assayed using an adaptation of the dinitrosalicylic acid method as described by Blatch \& Woods (1993). Sucrose hydrolase activities were expressed as $\mu \mathrm{mol}$ reducing sugar produced $\min ^{-1}$ (mg protein $)^{-1}$. The substrate specificity assays were carried out as in the standard saccharolytic assay, except that all substrates (sucrose, raffinose, melezitose, levan and inulin) were supplied at a concentration of $1 \%(\mathrm{w} / \mathrm{v})$. Fructokinase activity was assayed using the coupled assay described by Sprenger \& Lengeler (1988). Fructokinase activities were expressed as nmol or $\mu \mathrm{mol}$ fructose 6 -phosphate produced $\mathrm{min}^{-1}(\mathrm{mg} \text { protein })^{-1}$. Protein concentrations were determined using the method of Bradford (1976), with bovine serum albumin as the standard.

DNA-directed cell-free protein synthesis. Plasmid-encoded proteins were investigated using an E. coli DNA-directed cellfree transcription/translation system (Promega) according to the manufacturer's protocol. The proteins were labelled with $\mathrm{L}-\left[{ }^{35} \mathrm{~S}\right]$ methionine and resolved on $12 \%$ SDS-PAGE gels as described by Laemmli (1970). Molecular mass standards were obtained from Pharmacia.

\section{RESULTS}

\section{Isolation of the truncated scr gene cluster}

The $C$. beijerinckii genomic library constructed in pEcoR251 was screened in E. coli JM109 on sucroseMacConkey agar plates for sucrose-fermenting clones. After a $36 \mathrm{~h}$ incubation period, a single red colony was

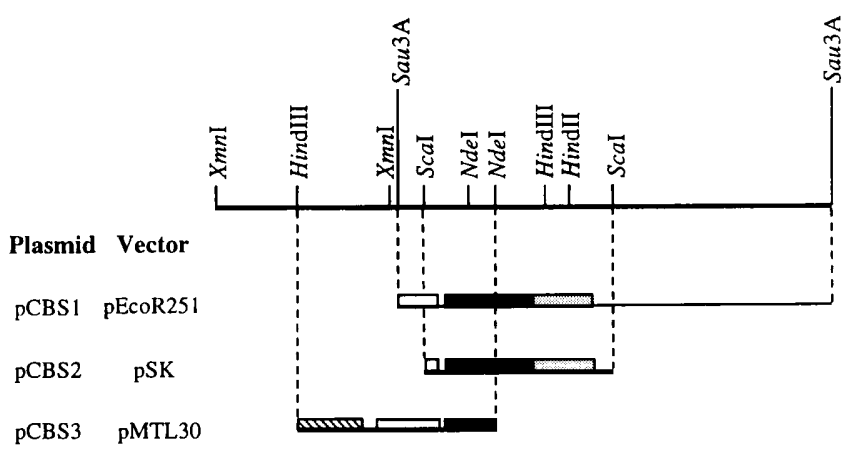

pCBS4 pACYC177

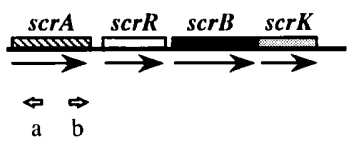

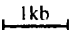

Fig. 1. Organization of the scr genes of the $C$. beijerinckii sucrose-utilization system. Transcriptional polarities are indicated by solid arrows. pCBS1 was isolated from a $C$. beijerinckii genomic library by its ability to confer a sucrosepositive phenotype on $E$. coli and has an insert of $6.8 \mathrm{~kb}$. pCBS2 was constructed by cloning the $3 \mathrm{~kb}$ Scal fragment into pSK. pCBS3 was recovered from the genome of $C$. beijerinckii strain CBSCRB, carrying multiple copies of a PMTL30 derivative integrated into the $s c r B$ gene. pCBS4 was constructed by amplifying a $1.2 \mathrm{~kb}$ fragment containing the $5^{\prime}$ region of scrA by inverse PCR, using primers $a$ and $b$, and cloning into the unique Smal site in PACYC177.

identified out of approximately 3000 colonies screened. The plasmid isolated from this colony ( $\mathrm{pCBS1}$ ) was found to contain a $6.8 \mathrm{~kb}$ insert (Fig. 1). The sequence that conferred a sucrose-positive phenotype was located on a $3 \mathrm{~kb} \mathrm{Scal}$ fragment (pCBS2) and DNA sequencing revealed a truncated ORF followed by two complete ORFs in the same orientation (Fig. 1). The truncated ORF (scrR) specified a protein with homology to members of the GalR-LacI family of transcriptional regulators, and the two ORFs downstream of $s c r R$ specified proteins with homology to sucrose hydrolases $(s c r B)$, and to fructokinases $(s c r K)$, respectively. No sucrose-transport genes were present on the insert in pCBS2 despite the fact that pCBS2 was able to confer a sucrose-positive phenotype on $E$. coli. This may be due to limited cell lysis releasing the cloned sucrose hydrolase.

\section{Isolation of the complete scrR gene by plasmid rescue}

The complete $s c r R$ gene was isolated by plasmid recovery from C. beijerinckii strain CBSCRB, which had been shown to carry multiple copies of a pMTL30 derivative integrated into the $s c r B$ gene (Table 1 ). The recovered plasmid, containing the adjacent chromosomal DNA, was designated pCBS3 (Fig. 1). Sequence analysis of the C. beijerinckii DNA inserted in pCBS3 indicated that although the complete $s c r R$ gene had been isolated, a truncated ORF was present upstream of $s c r R$, 
Table 2. Substrate specificity of sucrose hydrolase activity conferred on E. coli JM109 by pCBS2

Specific activity is expressed as $\mu \mathrm{mol}$ reducing sugar $\mathrm{min}^{-1}$ (mg protein $)^{-1}$. Values are means from three experiments, with standard deviations in parentheses. ND, No reducing sugars were detected after exposure to the indicated substrate for $60 \mathrm{~min}$.

\begin{tabular}{|c|c|c|c|c|c|}
\hline \multirow[t]{2}{*}{ Strain } & \multicolumn{5}{|c|}{ Specific enzyme activity } \\
\hline & Sucrose & Raffinose & Melezitose & Levan & Inulin \\
\hline E. coli JM109(pCBS2) & $15 \cdot 60(0 \cdot 31)$ & $8.84(0.51)$ & ND & ND & $0.24(0.08)$ \\
\hline E. coli JM109(pSK) & ND & $0.22(0.04)$ & ND & ND & $0 \cdot 18(0.07)$ \\
\hline
\end{tabular}

specifying a protein with homology to EIIBC ${ }^{\text {Scr }}$ PTS proteins $(s c r A)$.

\section{Isolation of the $5^{\prime}$ region of the scrA gene by inverse PCR}

Attempts were made to clone the $s c r A$ gene using the plasmid recovery strategy outlined above, but while plasmids equivalent to pCBS3 were readily recovered, regions further upstream could not be isolated. This suggested that the region upstream of the $s c r$ genes contained a strong promoter or DNA motif which was lethal to E. coli. Such an observation has been made for the sucrose-utilization system of $L$. lactis, where the promoter region of the $s c r B$ gene was found to be unstable when cloned on high-copy-number plasmids in E. coli (Rauch \& de Vos, 1992). It has also been noted that overexpression of membrane-bound PTS proteins may be lethal to host cells (Lengeler et al., 1994). An inverse-PCR strategy was therefore developed to amplify the $5^{\prime}$ region of the $s c r A$ gene and clone it into a low-copy-number plasmid, pACYC177, yielding pCBS4 (Fig. 1).

\section{Sucrose hydrolase and fructokinase activities conferred on $E$. coli by pCBS2}

Analysis of enzyme activities in cell-free extracts prepared from E. coli cells carrying pCBS2 confirmed the presence of both sucrose hydrolase and fructokinase activities. Investigation of the substrate specificity of the sucrose hydrolase indicated that it catalysed the hydrolysis of sucrose and raffinose but not melezitose, inulin and levan (Table 2). These data are consistent with the presence of a $\beta$-fructofuranosidase, able to hydrolyse the fructose moieties from low-molecularmass sugars (sucrose and raffinose), but not from the $(\beta 2 \rightarrow 1)$-linked fructose polymer inulin or the $(\beta 2 \rightarrow 6)$ linked fructose polymer levan. The sucrose hydrolase activity had a pH optimum slightly below $\mathrm{pH} 6 \cdot 0$, which corresponds almost exactly with that reported for the intracellular invertase activity of C. acetobutylicum IFP 912 (Looten et al., 1987). Maximum sucrose hydrolase activity was recorded between 35 and $40^{\circ} \mathrm{C}$, and the sucrose hydrolase was relatively stable at temperatures up to $30^{\circ} \mathrm{C}$ for $2 \mathrm{~h}$. Exposure to temperatures higher than $30^{\circ} \mathrm{C}$ resulted in a substantial loss of activity (data not shown).

The $s c r K$ gene product was proposed, on the basis of homology, to be a fructokinase of the ribokinase/ $p f k B$ sugar kinase family. Fructokinase activity could be demonstrated in cell-free extracts from E. coli JM109(pCBS2), with no detectable activity in the controls with plasmid vector only (results not shown). No fructokinase activity could be detected when ATP or $\mathrm{MgCl}_{2}$ was omitted from the assay mixture, in agreement with the reported characteristics of other fructokinases of this family (Fennington \& Hughes, 1996; Sprenger \& Lengeler, 1988). Maximum fructokinase activities were recorded between 20 and $35^{\circ} \mathrm{C}$, and the enzyme was unstable with respect to temperature, particularly when exposed to temperatures higher than $20{ }^{\circ} \mathrm{C}$ (results not shown). Subsequent fructokinase assays were conducted at $20^{\circ} \mathrm{C}$, which gave relatively high levels of activity while minimizing enzyme denaturation.

\section{Gene organization of the complete scrARBK gene cluster}

The $s c r A, s c r R, s c r B$ and $s c r K$ genes were clustered and present in the same orientation on the $C$. beijerinckii genome. As indicated above, scrA was proposed to encode an EIIBC ${ }^{\text {Scr }}$ protein, $s c r R$ to encode a regulatory protein of the GalR-LacI family, $s c r B$ to encode a sucrose hydrolase, and $s c r K$ to encode a fructokinase. The largest intergenic region $(190 \mathrm{bp})$ was present between $s c r A$ and $s c r R$, while $s c r R$ and $s c r B$ were separated by only $26 \mathrm{bp}$, and $s c r B$ and $s c r K$ overlapped (Fig. 2). Primer extension experiments using a scrAspecific primer, primer $c$, showed that $s c r A$ transcripts were initiated at an adenine residue $44 \mathrm{bp}$ upstream of the scrA ATG start codon (Fig. 3). The deduced -35 and -10 promoter sequence $\left(5^{\prime}-\mathrm{TTGACA}^{-} \mathrm{N}_{18^{-}}\right.$ TATCAT) lies between 51 and $80 \mathrm{bp}$ upstream of the $s c r A$ initiation codon (Fig. 2a), and shows considerable similarity to E. coli $\sigma^{70}$ and clostridial consensus promoter sequences (Young et al., 1989). A potential stem-loop structure which could act as a transcriptional terminator was identified 21-59 bp downstream of the proposed $s c r K$ termination codon $\left(-15 \mathrm{kcal} \mathrm{mol}^{-1}\right.$; 
(a)

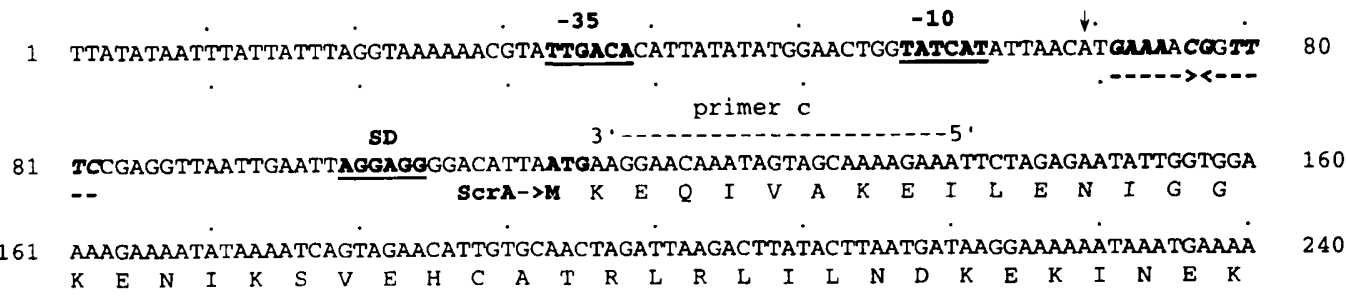

(b)

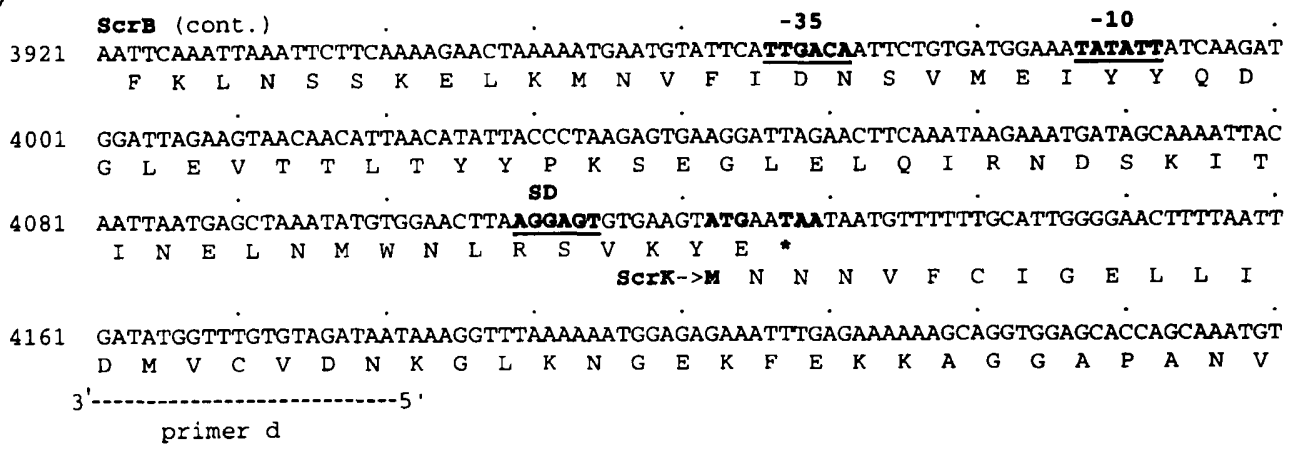

Fig. 2. Nucleotide sequence of the promoter regions preceding the scrA gene (a) and the scrk gene (b) of the $C$. beijerinckii scrARBK gene cluster, indicating the overlap between the scrB and scrk genes (b). Deduced amino acid sequences are shown in single-letter code below the coding sequences. Putative initiation and termination codons are indicated in bold type. Putative promoters ( -35 and -10 regions) and ribosome-binding sites (SD) are in bold type and underlined. The transcriptional start site of the scrARBK operon as determined by primer extension analyses is marked by a vertical arrow. The facing arrows, 31 to $\mathbf{4 2}$ bp upstream of the proposed scrA initiation codon, indicate an imperfect palindrome which may act as an operator site for a GalR-Lacl family regulatory protein. Primers $c$ and $d$ were used for primer extension experiments of the scrA and scrK genes respectively.

$-63 \mathrm{~kJ} \mathrm{~mol}^{-1}$ ) (Zuker \& Stiegler, 1981). An imperfect palindrome $\left(\mathrm{G}_{6} \mathrm{~A}_{5} \mathrm{~A}_{4} \mathrm{~A}_{3} \mathrm{~A}_{2} \mathrm{C}_{1} / \mathrm{G}_{1}{ }_{1} \mathrm{G}_{2} \mathrm{~T}^{\prime}{ }_{3} \mathrm{~T}_{4}{ }_{4} \mathrm{~T}_{5} \mathrm{C}_{6}^{\prime}\right)$ was identified between the putative $s c r A$ promoter and initiation codon (Fig. 2a), which may function as an operator at which a transcriptional regulator of the GalR-LacI family could bind (Weickert \& Adhya, 1992).

\section{Analysis of the deduced C. beijerinckii Scr proteins}

The deduced amino acid sequences encoded by the $C$. beijerinckii $s c r A, s c r R, s c r B$ and $s c r K$ genes were used to search the nucleic acid and protein databases using BLAST (NCBI; Devereux et al., 1984).

The scrA gene specifies a deduced protein of 451 aa with a calculated molecular mass of $47641 \mathrm{Da}$ and homology to previously studied EII ${ }^{\text {Scr }}$ proteins, with the highest amino acid sequence identity to the Strep. sobrinus ScrA (55.1\% identity over the corresponding EIIBC domains). Several particularly well-conserved regions have been identified for EIIBC ${ }^{\text {Scr }}$ proteins (Titgemeyer et al., 1996) and these regions are present in the deduced $C$. beijerinckii ScrA. The most highly conserved regions include the motif containing the proposed EIIB phosphorylation site and the GITE motif which has been proposed to be involved in phosphate and/or substrate binding (Lengeler et al., 1994). Hydrophobicity analysis revealed that the deduced ScrA protein has an $\mathrm{N}$ - terminal hydrophilic domain of approximately $112 \mathrm{aa}$, corresponding to the intracellular EIIB ${ }^{\text {Scr }}$ domain and linker region, while the remainder of the protein is essentially hydrophobic and corresponds to the EIIC Ser domain which is likely to be an integral membrane component (data not shown).

The C. beijerinckii scrR gene specifies a deduced protein of 330 aa with a calculated molecular mass of $36602 \mathrm{Da}$ and showing significant homology to members of the GalR-LacI family of transcriptional regulators $31.8 \%$ and $26 \%$ identity to Staph. xylosus and P. pentosaceous ScrR proteins respectively). Multiple sequence alignment of the ScrR proteins demonstrated that the region which was most highly conserved was the $\mathrm{N}$-terminal helix-turn-helix DNA-binding motif. In addition, the C. beijerinckii and Staph. xylosus ScrR proteins share several other conserved domains, corresponding to the regions of the LacI protein identified as being involved in inducer binding (Weickert \& Adhya, 1992). This suggests that the C. beijerinckii and Staph. xylosus ScrR proteins respond to the same ligand, probably sucrose 6phosphate (Gering \& Brückner, 1996).

In order to establish the relationship between the deduced C. beijerinckii ScrR and other GalR-Lacl family members, a phylogenetic analysis was conducted using the CLUSTAL w algorithm of Thompson et al. (1994). The recently isolated $\mathrm{ScrR}$ proteins were analysed, and the GalR-LacI regulatory proteins selected by Nguyen $\&$ 


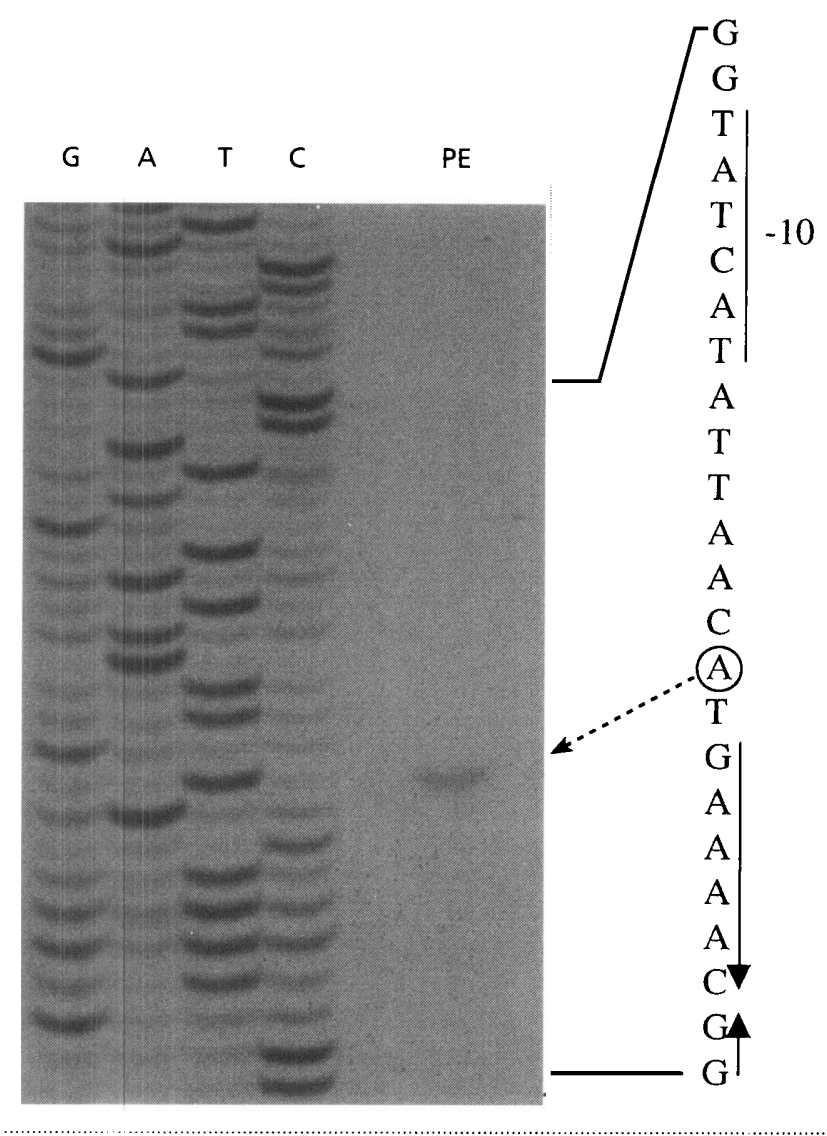

Fig. 3. Identification of the scr operon promoter and transcription initiation site: primer extension analysis of scr transcription in C. beijerinckii 8052 grown in GSMM containing sucrose $(0.25 \%, w / v)$. A DNA sequence ladder of the promoter region is shown on the left. $P E$, primer extension reaction product. Oligonucleotide primer $\mathrm{c}$ was used as the primer for both the DNA sequence and the primer extension reactions. The transcription initiation site at an A residue is indicated.

Saier (1995) were included for comparison. The resulting phylogenetic tree suggests that within the GalR-Lacl family, proteins involved in the regulation of sucrosecatabolic genes have evolved at least four times (A to D in Fig. 4). The first evolutionary line involves the Staph. xylosus and C. beijerinckii ScrR proteins (A), while the second line involves the $P$. pentosaceus and Strep. mutans ScrR proteins (B), which appear to have diverged from one another more recently than the $\mathrm{ScrR}$ proteins of Staph. xylosus and C. beijerinckii. The third and fourth lines lead to the CscR of E. coli $(\mathrm{C})$ and the closely related ScrR proteins of K. pneumoniae and Sal. typhimurium respectively (D). The proteins of the four evolutionary lines appear to be no more related to each other than to other GalR-LacI family members, despite their common role as regulators of sucrose metabolism.

The $s c r B$ gene specifies a deduced protein of 485 aa with a molecular mass of $57128 \mathrm{Da}$, which agrees with the value of $53.2 \mathrm{kDa}$ determined after cell-free transcription/translation and PAGE analysis (data not shown). The putative C. beijerinckii $\mathrm{ScrB}$ protein showed homology to $\beta$-fructofuranosidases of the glucosyl hydrolase family 32 (Henrissat \& Bairoch, 1993), with highest identity to a group of sucrose-6-phosphate hydrolases including the ScrB proteins from B. subtilis $(35 \cdot 6 \%), V$. alginolyticus $(35.5 \%)$ and Staph. xylosus $(35.2 \%)$ (Blatch et al., 1990; Brückner et al., 1993; Fouet et al., 1986). This would suggest that the product of the $s c r B$ gene normally hydrolyses sucrose 6-phosphate rather than sucrose. Seven regions of distinct homology have been reported for sucrose hydrolases from various organisms (Gunasekaran et al., 1990), and all of these are present in the putative C. beijerinckii ScrB protein.

The $s c r K$ gene specifies a deduced protein of 312 aa with a calculated molecular mass of $34297 \mathrm{Da}$. Analysis of the translation products of pCBS2 confirmed the presence of a protein band with an apparent molecular mass of $32 \mathrm{kDa}$, corresponding to the ScrK protein. The deduced ScrK protein showed significant homology to several prokaryotic as well as three eukaryotic ribokinase/ $p f k B$ family fructokinases, the highest being to those of K. pneumoniae (30.3\% identity) and V. alginolyticus (29.9\% identity). Multiple sequence alignment of the $C$. beijerinckii $\mathrm{ScrK}$ protein with several other members of the ribokinase/ $p f k B$ fructokinases revealed several relatively well-conserved regions; three of these are possibly involved in ATP binding (Bork et al., 1993) and two other domains may play a role in fructose binding (Fennington \& Hughes, 1996).

\section{Disruption of scrR and scrB genes in C. beijerinckii}

In order to investigate the role of the $s c r R$ gene product in transcriptional regulation, and to establish the importance of the $s c r$ operon to sucrose metabolism, the $s c r R$ and $s c r B$ genes were disrupted in C. beijerinckii by targeted integration, giving strains designated CBSCRR and CBSCRB respectively. Both mutant strains grew on media containing glucose $(10 \mathrm{mM})$ as the sole carbon source, but neither could grow when sucrose (10$100 \mathrm{mM}$ ) was supplied as the sole carbon source. The result clearly indicated that an intact $s c r$ operon was essential for growth on sucrose.

\section{Regulation of expression of the scrB and scrK genes in C. beijerinckii}

Sucrose hydrolase and fructokinase activities were assayed in C. beijerinckii cultures grown to $\mathrm{OD}_{600} 0 \cdot 4$ in the presence of sucrose, glucose, fructose, maltose or xylose. Both activities were induced in the presence of sucrose, but were low or absent when cells were grown on the other carbohydrates (data not shown). This regulation of enzyme activities associated with sucrose metabolism confirms previous findings by Tangney et al. (1998), where PEP-dependent sucrose phosphorylation activity was reported to be induced in sucrose-grown $C$. beijerinckii cells, but not in xylose- or fructose-grown cells.

Northern blot analysis was undertaken to investigate the transcription of the $\mathrm{scr}$ gene cluster and to confirm the role of the $s c r R$ gene, encoding a GalR-LacI-like 


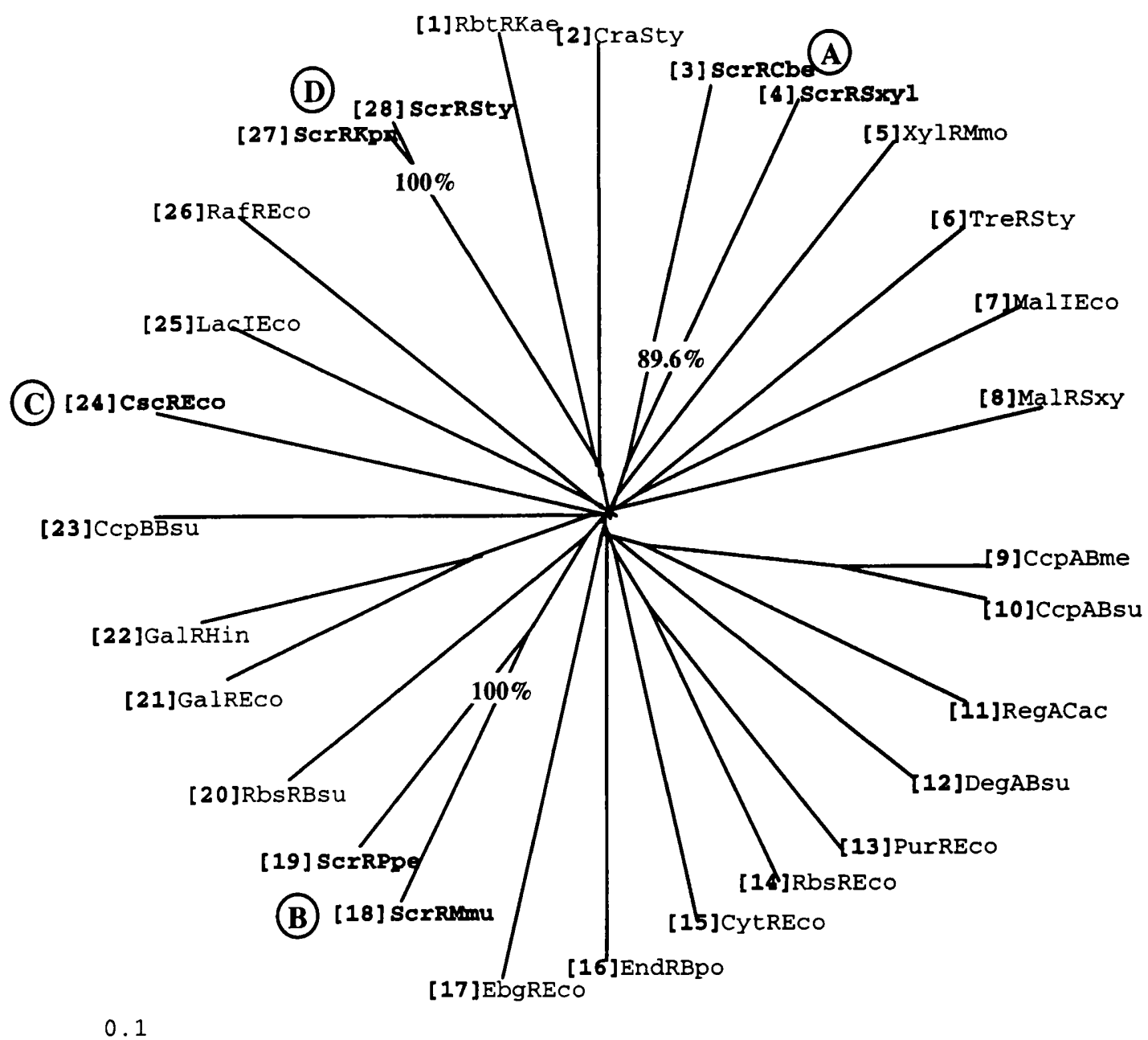

Fig. 4. Phylogenetic tree for the proteins of the GalR-Lacl family. Branch lengths are approximately proportional to the amount of sequence difference. The scale of 0.1 indicates $10 \%$ amino acid sequence divergence. The four evolutionary lines involving regulators of sucrose-catabolic genes are shown ( $A$ to $D$ ), and bootstrap values, as a percentage of 1000 trials, are indicated. Sequence abbreviations and accession numbers are: [1] RbtRKae, Klebsiella aerogenes ribitol repressor, sp: P07760; [2] CraSty, Salmonella typhimurium catabolite repressor/activator protein, sp: P21930; [3] ScrRCbe, Clostridium beijerinckii ScrR; [4] ScrRSxyl, Staphylococcus xylosus ScrR, EMBL: X67744; [5] XylRMmo, Morganella morganii xylitol repressor, gb: L34345; [6] TreRSty, Sal. typhimurium trehalose repressor, sp: P36674; [7] MallEco, E. coli maltose repressor, sp: P18811; [8] MalRSxy, Staph. xylosus maltose repressor, PIR: S44187; [9] CcpABme, Bacillus megaterium catabolite control protein A (CcpA), gb: L26052; [10] CcpABsu, Bacillus subtilis CcpA, sp: P25144; [11] RegACac, Clostridium acetobutylicum RegA, gb: L14685; [12] DegABsu, B. subtilis degradation enzyme activator, sp: P37947; [13] PurREco, E. coli purine repressor, sp: P15039; [14] RbsREco, E. coli ribose repressor, gb: L10328; [15] CytREco, E. coli cytidine repressor, sp: P06964; [16] EndRBpo, Bacillus polymyxa endogluconase repressor, sp: P27871; [17] EbgREco, $E$. coli evolved $\beta$-galactosidase repressor, sp: P06846; [18] ScrRMmu, Streptococcus mutans ScrR, gb: U46902; [19] ScrRPpe, Pediococcus pentosaceus ScrR, sp: P43472; [20] RbsRBsu, B. subtilis ribose repressor, Sp: P36944; [21] GalREco, E. coli GalR, sp: P03024; [23] GalRHin, Haemophilus influenzae GalR, sp: P31766; [23] CcpBBsu, B. subtilis Catabolite control protein B (CCPB), sp: P37517; [24] CscREco, E. coli CsCR, sp: P40715; [25] LaclEco, E. coli lactose repressor, sp: P03023; [26] RafREco, E. coli raffinose repressor, sp: P21867; [27] ScrRKpn, K. pneumoniae ScrR, sp: P37076; [28] ScrRSty, Sal. typhimurium ScrR, sp: P37077.

regulatory protein. Probes specific for the $s c r A$, scrR, $s c r B$ and $s c r K$ transcripts were hybridized against RNA extracted from $C$. beijerinckii cells grown on sucrose, glucose, fructose, xylose or maltose. A predominant $5.0 \mathrm{~kb}$ transcript was identified by each of the $s c r$ probes in RNA isolated from sucrose-grown cells, but was not present in RNA extracted from cells grown on glucose, fructose, xylose or maltose (Fig. 5). The size of the transcript $(5.0 \mathrm{~kb})$ correlates with the size of the four genes involved (4946 bp from sequence data). These data confirm that the scr genes are expressed as an operon and that transcription is induced by sucrose.

\section{RNA analysis of the scrB and scrR mutant strains}

The effect of $s c r R$ and $s c r B$ disruption on the expression of the $s c r$ operon was determined by Northern blot analysis using a probe specific for the $s c r A$ transcript. 
(a)

(b)

12345 (c)

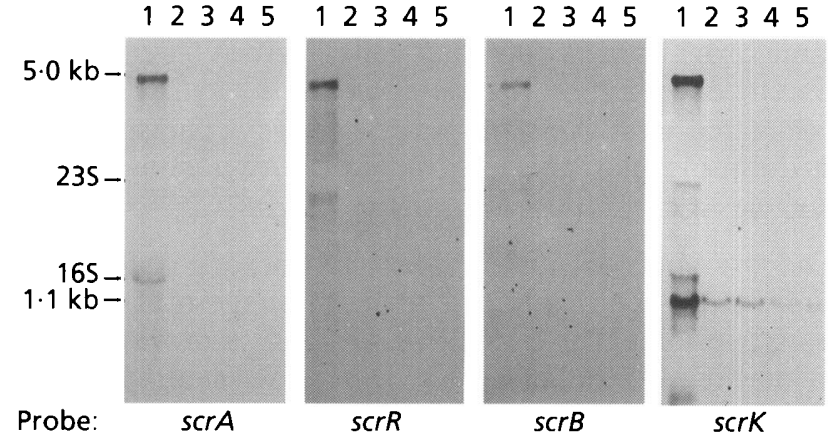

(d)

Fig. 5. Northern blot hybridization of RNA isolated from $C$. beijerinckii NCIMB 8052 grown to exponential phase in GSMM medium containing $0.25 \%(\mathrm{w} / \mathrm{v})$ of the respective carbohydrate. Lanes 1-5, sucrose, glucose, fructose, xylose and maltose respectively. Panels (a), (b), (c) and (d) were hybridized with probes specific for the scrA, scrR, scr $B$ and scrK transcripts respectively.

The $s c r A$ gene lies upstream of $s c r R$ and $s c r B$ and would therefore not be subject to the polar effects of disruptions in either of these genes. Total RNA was extracted from wild-type C. beijerinckii cells grown with $0.25 \%(\mathrm{w} / \mathrm{v})$ sucrose, glucose or xylose. Since the C. beijerinckii scrR and $s c r B$ mutants were unable to grow on sucrose, RNA could only be extracted from cells grown on $0.25 \%$ $(\mathrm{w} / \mathrm{v})$ glucose and xylose. As shown in Fig. 6, the $s c r A$ transcript was detected in the wild-type C. beijerinckii strain only in RNA from sucrose-grown cells, and not in that from glucose- or xylose-grown cells (Fig. 6a, lanes 1,2 and 3). In the scrR mutant, CBSCRR, scrA transcripts were detected in RNA extracted from both glucose-and xylose-grown cells. The $5.0 \mathrm{~kb} s \mathrm{sr}$ operon transcript was not present and transcripts with a wide range of sizes were detected, probably representing transcription initiated at the $s c r A$ promoter which had extended into the multiple tandem repeats of plasmids integrated into the $s c r R$ gene. Clearly, a disruption of $s c r R$ had resulted in expression of the $s c r$ operon under non-inducing conditions, confirming that $s c r R$ encoded a negative regulator of $s c r$ operon transcription. A $s c r A$ transcript was not detected in the $s c r B$ mutant grown on either glucose or xylose, because the intact $s c r R$ gene product would have repressed $s c r$ operon transcription.

While Northern blot analysis of wild-type C. beijerinckii indicated that all four $s c r$ genes were co-transcribed as a $5.0 \mathrm{~kb}$ operon, an additional $1.1 \mathrm{~kb}$ transcript was detected with a scrK-specific probe (Fig. 5d). This transcript was constitutively expressed in the presence of the different carbohydrate substrates; however, the intensity of the band was significantly greater in RNA from sucrose-grown cells. Analysis of RNA isolated from the CBSCRR and CBSCRB mutants using the scrK probe indicated that the $1 \cdot 1 \mathrm{~kb}$ transcript was expressed despite disruption of the $s c r$ operon under different growth conditions (Fig. 6b). A possible explanation is that this transcript represents an additional scrK tran-

(a)

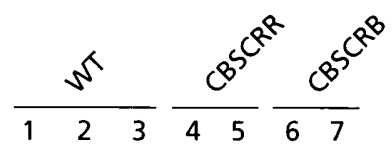

(b)
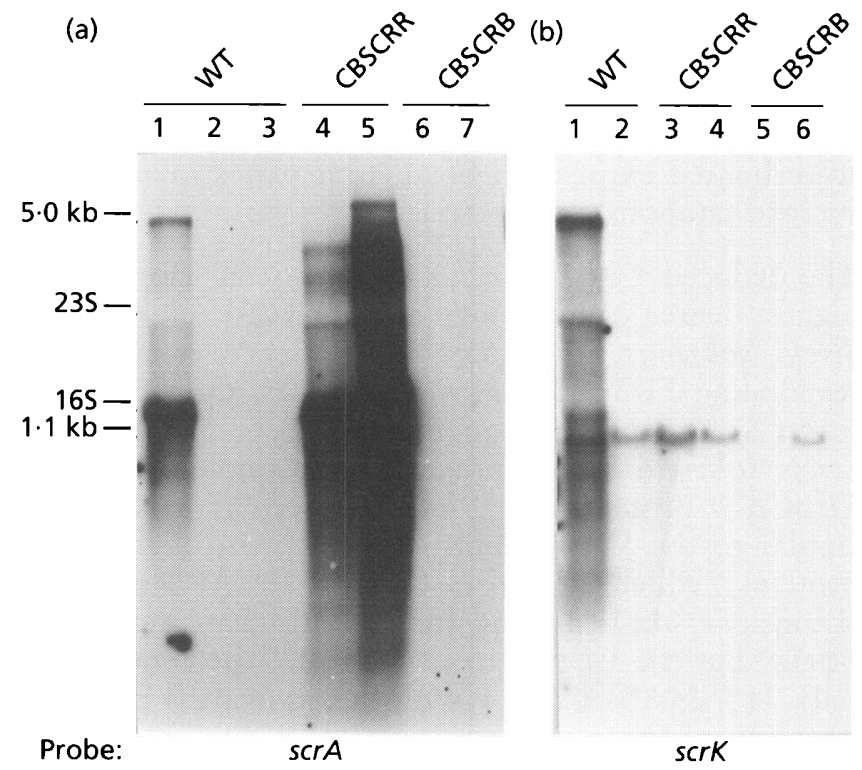

Fig. 6. Northern blot analysis of C. beijerinckii wild-type (WT) and mutant strains CBSCRR and CBSCRB. RNA was extracted from cells grown in GSMM with carbohydrates supplied at $0.25 \%(w / v)$, and hybridized with (a) a scrA-specific probe or (b) a scrk-specific probe. (a) RNA extracted from wild-type $C$. beijerinckii cells grown on sucrose, glucose or xylose (lanes 1, 2 and 3 respectively); or from $C$. beijerinckii CBSCRR or CBSCRB cells grown on glucose (lanes 4 and 6 ) or xylose (lanes 5 and 7) respectively. (b) RNA extracted from wild-type C. beijerinckii cells grown on sucrose or glucose (lanes 1 and 2) or from $C$. beijerinckii CBSCRR or CBSCRB cells grown on glucose (lanes 3 and 5) or xylose (lanes 4 and 6).

script expressed from a promoter within the scr operon. A putative promoter has been identified upstream of $s c r K$, within the coding region of $s c r B$ (Fig. 2b), but primer extension analysis using primer $\mathrm{d}$ (Fig. 2) failed to confirm this as a functional promoter. The $1.1 \mathrm{~kb}$ transcript is therefore more likely to represent the mRNA of an independent gene with homology to $s c r K$.

\section{DISCUSSION}

Nucleotide sequence analysis indicated that the $C$. beijerinckii sucrose-utilization cluster consisted of four genes, $s c r A, s c r R, s c r B$ and $s c r K$, encoding proteins capable of catalysing all the steps required for sucrose catabolism. In addition, this was the only sucrosecatabolic pathway in C. beijerinckii because mutants in either $s c r R$ or $s c r B$ were unable to grow on sucrose as a sole carbohydrate source. These findings confirm that sucrose utilization involves PTS-dependent sucrose transport, resulting in the accumulation of intracellular sucrose 6-phosphate. This would in turn be hydrolysed by the sucrose-6-phosphate hydrolase, releasing glucose 6-phosphate and fructose, which would be incorporated into the glycolytic pathway once the fructose had been phosphorylated by the product of the scrK gene, the fructokinase. Unlike the other sucrose-utilization regulons reported thus far, the $s c r$ genes constitute an operon. 
RNA analysis confirmed that the genes were cotranscribed on a $5 \mathrm{~kb}$ mRNA transcript with the transcriptional start site situated 44 bp upstream of the $s c r A$ gene. To our knowledge, this is the first example of co-ordinated expression of all four genes involved in sucrose catabolism in bacteria.

The deduced C. beijerinckii ScrA protein showed the highest degree of homology at the amino acid level to Strep. sobrinus ScrA $(55.1 \%$ identity over the corresponding EIIBC domains). However, the C. beijerinckii ScrA represents an EIIBC ${ }^{\mathrm{Scr}}$ protein while the Strep. sobrinus ScrA represents an example of a fused EIIBCA $^{\text {Scr }}$ protein. Strep. sobrinus ScrA is structurally similar to the Strep. mutans and P. pentosaceus ScrA proteins, which are also fused EIIBCA ${ }^{\text {Ser }}$ proteins (Lengeler et al., 1994), and undoubtedly share a common origin, but the C. beijerinckii EIIBC $^{\text {scr }}$ protein shares only $34 \cdot 5-34.8 \%$ identity with the equivalent EIIBC ${ }^{\text {Ser }}$ domains of these two proteins. Since the scrA of $C$. beijerinckii appears to encode an EIIBC ${ }^{\text {Scr }}$ protein, it must interact with an EIIA domain encoded elsewhere on the chromosome. It is possible that a separate EIIA ${ }^{\text {scr }}$ domain is present in C. beijerinckii; however, in $B$. subtilis the EIIA ${ }^{\text {Glc }}$ domain of the EIICBA ${ }^{\text {Glc }}$ protein has been shown to phosphorylate EIIB $^{\text {Scr }}$ (Sutrina et al., 1990). In studies with the K. pneumoniae, Sal. typhimurium and $V$. alginolyticus sucrose-utilization systems cloned into E. coli, it was demonstrated that EIIBC ${ }^{\text {Scr }}$ dependent sucrose uptake required the presence of a functional E. coli EIIA $^{\text {Glc }}$ (Blatch et al., 1990; Lengeler $e t$ al., 1982; Sprenger \& Lengeler, 1988). It is therefore conceivable that the C. beijerinckii EIIB $^{\text {Scr }}$ domain interacts with a shared EIIA domain, probably that of the glucose PTS.

The scrK gene product indicated homology to several prokaryotic as well as three eukaryotic fructokinases of the ribokinase/ $p f k B$ family. ATP-dependent fructokinases occur in two non-homologous families, the ribokinase/ $p f k B$ family and the ROK/hexokinase family (Bork et al., 1993; Titgemeyer et al., 1994). Genes encoding proteins from both families have been found to be associated with sucrose-utilization gene clusters. However, it is worth noting that the C. beijerinckii $\mathrm{ScrK}$ represents the first complete sequence of a ribokinase/ $p f k B$ family fructokinase associated with a sucrose-utilization gene cluster in a Gram-positive organism. In other Gram-positive bacteria, fructokinase-encoding genes are either not clustered with sucrose-catabolic genes or encode ROK/hexokinase family fructokinases (Thompson et al., 1991; Sato et al., 1993; GenBank accession L32093).

The $C$. beijerinckii scr gene cluster has a number of similarities to the sucrose PTS regulon of Staph. xylosus. The Staph. xylosus system has been reported to consist of an independent $s c r A$ and a $s c r R B$ gene cluster (Brückner et al., 1993; Gering \& Brückner, 1996; Wagner et al., 1993). However, it was noted during the sequence analysis that a gene encoding a ribokinase/ $p f k B$ family fructokinase appears to lie immedi- ately downstream of the Staph. xylosus scrB, making the final gene arrangement $s c r R B K$. This is precisely the same order as the equivalent genes of the C. beijerinckii system except that the scrA of Staph. xylosus is not associated with the remaining $s c r$ genes. The similarity in the molecular organization of the two gene clusters suggests a common evolutionary origin.

The presence of $s c r R$ in the $s c r$ operon, encoding a GalR-LacI-like regulatory protein, suggested that the transcription of the C. beijerinckii scr system was subject to negative regulation by the $s c r R$ gene product. Northern blot analysis demonstrated that the $s c r A R B K$ genes were transcribed when $C$. beijerinckii had been grown in the presence of sucrose but were repressed in the presence of other carbohydrate substrates. In the $C$. beijerinckii scrR mutant, the scr operon was constitutively transcribed under non-inducing conditions, confirming that the $s c r R$ gene product played a negative regulatory role. While the precise details of this mechanism remain unclear, analogy with other GalR-LacIlike regulatory proteins suggests that in the absence of sucrose, the C. beijerinckii ScrR may repress transcription by binding to imperfectly palindromic operator sites in the vicinity of the $s c r$ operon promoter. A potential operator site was identified between the putative scrA promoter and initiation codon. It is of interest to note that this operator sequence differs from the consensus sequence of catabolite-responsive element (CRE) sites by only 1 bp (Hueck et al., 1994; Weickert \& Chambliss, 1990). Genes encoding CcpA homologues have been identified from both C. acetobutylicum P262 (Davison et al., 1995) and C. beijerinckii (RegB). It is possible that the operator site may also be the target of a regulatory protein such as CcpA, which mediates catabolite repression in several Gram-positive bacteria (Henkin et al., 1991; Hueck et al., 1994; Saier et al., 1996). Gering \& Brückner (1996) demonstrated that the deletion of $4 \mathrm{bp}$ of the right arm of a similar operator site in the scrB gene of Staph. xylosus eliminated not only the sucrose-specific regulation of $s c r B$ expression but also the glucose-mediated repression observed in the wild-type strain.

The location of the gene for the $\mathrm{ScrR}$ regulatory protein itself, within the inducible $s c r A R B K$ operon, is somewhat unusual. In other sucrose-utilization regulons, with the exception of that of L. lactis (Rauch \& de Vos, 1992), the corresponding $s c r R$ genes are independently transcribed. The C. beijerinckii regulator protein has highest sequence homology to the ScrR protein of Staph. xylosus; however, the regulation of the gene clusters differs. In Staph. xylosus, the scrR and $s c r B$ genes are independently transcribed, and inactivation of the $s c r R$ gene leads to constitutive expression of the downstream scrB gene (Gering \& Brückner, 1996). In contrast, the $C$. beijerinckii $s c r R$ is transcribed as part of the $s c r$ operon and therefore is negatively autoregulated. It would be unnecessary for large amounts of ScrR to be synthesized, as $s c r$ operon transcripts accumulate under inducing conditions. Indeed, if large amounts of ScrR were produced, this could conceivably lead to the repression 
of scr operon transcription, even in the presence of inducer. Gram-positive bacteria are stringent in their requirements for high-level initiation of protein synthesis. In $B$. subtilis, translational yield can be substantially reduced if ribosome-binding sites and initiation codons are separated by less than $6 \mathrm{bp}$ (Vellanoweth \& Rabinowitz, 1992). While the proposed ribosome-binding site and initiation codon of the $\operatorname{scr} A$, $s c r B$ and $s c r K$ genes in $C$. beijerinckii are separated by the conventional 7-9 bp, only 5 bp separate the ribosome-binding site and initiation codon in $s c r R$. It is possible that this suboptimal spacing may limit translation of $s c r R$, in order to allow for optimal expression of the scr operon and the build-up of gene products other than ScrR while the inducer is present.

\section{ACKNOWLEDGEMENTS}

We are most grateful to G. L. Blatch for assistance in the initial stages and to D. R. Woods, V.R. Abratt and W. J. Mitchell for their advice and stimulating discussions. This work was supported by grants from the Foundation for Research Development, South Africa.

\section{REFERENCES}

Arnaud, M., Vary, P., Zagorec, M., Klier, A., Debarbouille, M., Postma, P. \& Rapoport, G. (1992). Regulation of the sacPA operon of Bacillus subtilis : identification of phosphotransferase system components involved in SacT activity. J Bacteriol 174, 3161-3170.

Ausubel, F. M., Brent, R., Kingston, R. E., Moore, D. D., Seidman, J. G., Smith, J. A. \& Struhl, K. (1989). Current Protocols in Molecular Biology, vol. 1. New York: Wiley.

Blatch, G. L. \& Woods, D. R. (1993). Molecular characterisation of a fructanase produced by Bacteroides fragilis BF-1. J Bacteriol $175,30.58-3066$.

Blatch, G. L., Scholle, R. R. \& Woods, D. R. (1990). Nucleotide sequence and analysis of the Vibrio alginolyticus sucrose uptakeencoding region. Gene 95, 17-23.

Bockmann, J., Heuel, H. \& Lengeler, J. W. (1992). Characterisation of a chromosomally encoded, non-PTS metabolic pathway for sucrose utilisation in Escherichia coli EC3132. Mol Gen Genet 235, 22-32.

Bork, P., Sander, C. \& Valencia, A. (1993). Convergent evolution of similar enzymatic function on different protein folds: the hexokinase, ribokinase, and galactokinase families of sugar kinases. Protein Sci 2, 31-40.

Bradford, M. M. (1976). A rapid and sensitive method for quantitation of microgram quantities of protein utilising the principle of protein-dye binding. Anal Biochem 72, 248-254.

Bruckner, R., Wagner, E. \& Gotz, F. (1993). Characterisation of a sucrase gene from Staphylococcus xylosus. J Bacteriol 175, $851-8.5$

Chang, A. C. Y. \& Cohen, S. N. (1978). Construction and characterisation of amplifiable multicopy DNA cloning vehicles derived from the P15A cryptic miniplasmid. J Bacteriol 134, 1141-1156.

Chen, Y. Y., Lee, L. N. \& LeBlanc, D. J. (1993). Sequence analysis of scrA and scrB from Streptococcus sobrinus 6715. Infect Immun $61,2602-2610$.

Collett, H. J., Woods, D. R. \& Reid, S. J. (1997). Characterisation of a transposon-induced pleiotropic mutant of Clostridium acetobutylicum P262. Anaerobe 3, 411-421.
Davison, S. P., Santangelo, J. D., Reid, S. J. \& Woods, D. R. (1995). A Clostridium acetobutylicum regulator gene (repA) affecting amylase production in Bacillus subtilis. Microbiology 141, 989-996.

Devereux, J., Haberti, P. \& Smithies, O. (1984). A comprehensive set of sequence analysis programs for the VAX. Nucleic Acids Res 12, 387-395.

Fennington, G. J. \& Hughes, T. A. (1996). The fructokinase from Rhizobium leguminosarum biovar trifolii belongs to group I fructokinase enzymes and is encoded separately from other carbohydrate metabolism enzymes. Microbiology 142, 321-330.

Fouet, A., Klier, A. \& Rapoport, G. (1986). Nucleotide sequence of the sucrase gene of Bacillus subtilis. Gene 45, 221-225.

Fouet, A., Arnaud., M., Klier, A. \& Rapoport, G. (1987). Bacillus subtilis sucrose-specific enzyme II of the phosphotransferase system : expression in Escherichia coli and homology to enzymes II from enteric bacteria. Proc Natl Acad Sci USA 84, 8773-8777.

Gering, M. \& Bruckner, R. (1996). Transcriptional regulation of the sucrase gene of Staphylococcus xylosus by the repressor ScrR. J Bacteriol 178, 462-469.

Gunasekaran, P., Karunakaran, T., Cami, B., Mukundan, A. G., Preziosi, L. \& Baratti, J. (1990). Cloning and sequencing of the sacA gene: characterisation of a sucrase from Zymomonas mobilis. J Bacteriol 172, 6727-6735.

Henkin, T. M., Grundy, F. J., Nicholson, W. L. \& Chambliss, G. H. (1991). Catabolite repression of alpha-amylase gene expression in Bacillus subtilis involves a trans-acting gene product homologous to the Escherichia coli lacl and galR repressors. Mol Microbiol 5, 575-584.

Henrissat, B. \& Bairoch, A. (1993). New families in the classification of glycosyl hydrolases based on amino acid sequence similarities. Biochem J 293, 781-788.

Hueck, C. J., Hillen, W. \& Saier, M. H., Jr (1994). Analysis of a cisactive sequence mediating catabolite repression in Gram-positive bacteria. Res Microbiol 145, 503-518.

Jahreis, K. \& Lengeler, J. W. (1993). Molecular analysis of two ScrR repressors and of a ScrR-FruR hybrid repressor for sucrose and D-fructose specific regulons from enteric bacteria. Mol Microbiol 9, 195-209.

Johnson, J.L. \& Chen, J.-S. (1995). Taxonomic relationships among strains of Clostridium acetobutylicum and other phenotypically similar organisms. FEMS Microbiol Rev 17, 233-240.

Jones, D. T. \& Keis, S. (1995). Origins and relationships of industrial solvent-producing clostridial strains. FEMS Microbiol Rev 17, 223-232.

Jones, D. T., van der Westhuizen, A., Long, S., Allcock, E. R. Reid, S. J. \& Woods, D. R. (1982). Solvent production and morphological changes in Clostridium acetobutylicum. Appl Environ Microbiol 43, 1434-1439.

Keis, S., Bennet, C. F., Ward, V. K. \& Jones, D. T. (1995). Taxonomy and phylogeny of industrial solvent-producing clostridia. Int J Syst Bacteriol 45, 693-705.

Laemmli, U. K. (1970). Cleavage of structural proteins during the assembly of the head of bacteriophage T4. Nature 227, 680-685.

Lengeler, J.W., Mayer, R. J. \& Schmid, K. (1982). Phosphoenolpyruvate-dependent phosphotransferase system enzyme III and plasmid-encoded sucrose transport in Escherichia coli K-12. J Bacteriol 151, 468-471.

Lengeler, J. W., Jahreis, K. \& Wehmeier, U. F. (1994). Enzymes II of the phosphoenolpyruvate-dependent phosphotransferase systems: their structure and function in carbohydrate transport. Biochim Biophys Acta 1188, 1-28. 
Looten, P., Blanchet, D. \& Vandecasteele, J. P. (1987). The $\beta$ fructofuranosidase activities of a strain of Clostridium acetobutylicum grown on inulin. Appl Microbiol Biotechnol 25, 419-425.

Mitchell, W. J., Shaw, J. E. \& Andrews, L. (1991). Properties of the glucose phosphotransferase system of Clostridium acetobutylicum NCIB 8052. Appl Environ Microbiol 57, 2534-2539.

Mitchell, W. J., Albasheri, K. A. \& Yazadanian, M. (1995). Factors affecting utilisation of carbohydrates by clostridia. FEMS Microbiol Rev 17, 317-329.

Nguyen, C. C. \& Saier, M. H., Jr (1995). Phylogenetic, structural and functional analyses of the LacI-GalR family of bacterial transcription factors. FEBS Lett 377, 98-102.

Rauch, P. J. \& de Vos, W. M. (1992). Transcriptional regulation of the Tn5276-located Lactococcus lactis sucrose operon and characterisation of the $s a c A$ gene encoding sucrose-6-phosphate hydrolase. Gene 121, 55-61.

Saier, M. H. \& Reizer, J. (1992). Proposed uniform nomenclature for the proteins and protein domains of the bacterial phosphoenolpyruvate:sugar phosphotransferase system. J Bacteriol 174, 1433-1438.

Saier, M. H., Chauvaux, S., Cook, G. M., Deutscher, J., Paulsen, I. T., Reizer, J. \& Ye, J.-J. (1996). Catabolite repression and inducer control in gram-positive bacteria. Trends Biochem Sci 20, 267-271.

Sambrook, J., Fritsch, E. F. \& Maniatis, T. (1989). Molecular Cloning: a Laboratory Manual, 2nd edn. Cold Spring Harbor, NY: Cold Spring Harbor Laboratory.

Sato, Y., Poy, F., Jacobson, G. R. \& Kuramitsu, H. K. (1989). Characterisation and sequence analysis of the $s c r A$ gene encoding enzyme II $^{\text {scr }}$ of the Streptococcus mutans phosphoenolpyruvatedependent sucrose phosphotransferase system. J Bacteriol 171, 263-271.

Sato, Y., Yamamoto, Y., Kizaki, H. \& Kuramitsu, H. K. (1993). Isolation, characterisation and sequence analysis of the $s c r K$ gene encoding fructokinase of Streptococcus mutans. J Gen Microbiol $139,921-927$.

Sprenger, G. A. \& Lengeler, J. W. (1988). Analysis of sucrose catabolism in Klebsiella pneumoniae and in $\mathrm{Scr}^{+}$derivatives of Escherichia coli K12. J Gen Microbiol 134, 1635-1644.

Steinmetz, M. (1993). Carbohydrate catabolism: pathways, enzymes, genetic regulation, and evolution. In Bacillus subtilis and Other Gram-positive Bacteria, pp. 157-170. Edited by A. L. Sonenshein. Washington, DC: American Society for Microbiology.

Sutrina, S. I., Reddy, P., Saier, M. H. \& Reizer, J. (1990). The glucose permease of Bacillus subtilis is a single polypeptide chain that functions to energise the sucrose permease. J Biol Chem 265, 18581-18589.

Tangney, M., Rousse, C., Yazdanian, M. \& Mitchell, W. J. (1998). Sucrose transport and metabolism in Clostridium beijerinckii NCIMB 8052. J Appl Microbiol 84, 914-919.

Thompson, J., Sackett, D. L. \& Donkersloot, J. A. (1991). Purifi- cation and properties of fructokinase I from Lactococcus lactis. Localization of $s c r K$ on the sucrose-nisin transposon Tn5306. J Biol Chem 266, 22626-22633.

Thompson, J. D., Higgins, D. G. \& Gibson, T. J. (1994). CLUSTAL w : improving the sensitivity of progressive multiple sequence alignment through sequence weighting, position specific gap penalties and weight matrix choice. Nucleic Acids Res 22, 4673-4680.

Titgemeyer, F., Reizer, J., Reizer, A. \& Saier, M. H., Jr (1994). Evolutionary relationships between sugar kinases and transcriptional repressors in bacteria. Microbiology 140, 2349-2354.

Titgemeyer, F., Jahreis, K., Ebner, R. \& Lengeler, J. W. (1996). Molecular analysis of the $s c r A$ and $s c r B$ genes from Klebsiella pneumoniae and plasmid pUR400, which encode the sucrose transport protein Enzyme II ${ }^{\text {Scr }}$ of the phosphotransferase system and a sucrose-6-phosphate invertase. Mol Gen Genet 250, 197-206.

Vellanoweth, R. L. \& Rabinowitz, J. C. (1992). The influence of ribosome-binding-site elements on translation efficiency in Bacillus subtilis and Escherichia coli in vivo. Mol Microbiol 6, 1105-1114.

Wagner, E., Gotz, F. \& Brückner, R. (1993). Cloning and characterisation of the $s c r A$ gene encoding the sucrose-specific Enzyme II of the phosphotransferase system from Staphylococcus xylosus. Mol Gen Genet 241, 33-41.

Weickert, M. J. \& Adhya, S. (1992). A family of bacterial regulators homologous to Gal and $\mathrm{Lac}$ repressors. J Biol Chem 267, 15869-15874.

Weickert, M. J. \& Chambliss, G. H. (1990). Site-directed mutagenesis of a catabolite repression operator sequence in Bacillus subtilis. Proc Natl Acad Sci USA 87, 6238-6242.

Wilkinson, S. R. \& Young, M. (1994). Targeted integration of genes into the Clostridium acetobutylicum chromosome. Microbiology 140, 89-95.

Williams, D. R., Young, D. I. \& Young, M. (1990). Conjugative plasmid transfer from Escherichia coli to Clostridium acetobutylicum. J Gen Microbiol 136, 819-826.

Woods, D. R. (1993). The Clostridia and Biotechnology. Boston: Butterworth-Heinemann.

Young, M., Minton, N. P. \& Staudenbauer, W. L. (1989). Recent advances in the genetics of the clostridia. FEMS Microbiol Rev 63, 301-326.

Youngleson, J. S., Lin, F.-P., Reid, S. J. \& Woods, D. R. (1995). Structure and transcription of genes within the $\beta$-hbd-adh1 region of Clostridium acetobutylicum P262. FEMS Lett 125, 185-192.

Zabeau, M. \& Stanley, K. K. (1982). Enhanced expression of Cro$\beta$-galactosidase fusion proteins under the control of the $P_{R}$ promoter of the bacteriophage lambda. EMBO J 1, 1217-1224.

Zuker, M. \& Stiegler, P. (1981). Optimal computer folding of large RNA sequences using thermodynamics and auxiliary information. Nucleic Acids Res 9, 133-148.

Received 5 November 1998; revised 1 March 1999; accepted 5 March 1999. 